\title{
Peer review in medical journals
}

Peer review of manuscripts submitted to general medical journals improves the quality of published papers and prevents the publication of much poor science. The journals with the highest standards extend their influence widely, since the papers they reject flow, like water, downhill and along paths of least resistance to lesser journals-but in the process some are purified and others evaporate.

It is not by chance that both authors and readers prefer the most demanding journals-those that review submissions the most stringently and reject the greatest proportion of the papers they receive. Peer review is wired into the circuits of science. The editor of the $B M \mathcal{F}$, Stephen Lock, shows in his recent book how peer review plays a vital part in testing science research at the four phases depicted by Ziman: the inchoate phase, in which there are more hypotheses than facts; then the phase of discovery, which usually starts with a sentinel study that threatens the old belief; next the dynamic phase of breakthrough, when keen minds and skilled fingers hustle to produce arresting results; and, finally, a plodding period of consolidation, enlivened by a few attempts at refutation.

Most of Lock's book, a monograph based on his 1985 Rock Carling lecture, is devoted to describing peer review and considering how to improve it, but he keeps a broad perspective and at several points wonders aloud if the current system is justified. Certainly the most vexed aspect of peer review is the review of grant proposals. Confidence in this process has crumbled so much that it has been suggested that the citation record of mature researchers is a better criterion of the value of their proposed research than the research proposal itself. ${ }^{2}$

For completed work, however, Lock's thorough investigation adds up to a strong case for something close to the system we are now using. Indeed, his study of a cohort of 1558 manuscripts submitted to the $B M \mathcal{F}$ showed that the earlier the paper was rejected by the journal's rather complex algorithm of review the less likely it was to be published subsequently in a high impact journal. Some would claim this points only to self validation by an elite, but a more reasonable conclusion is that peer review is indeed the linchpin of science. ${ }^{1}$

Yet, while affirming its value and validity, Lock remains somewhat edgy about peer review. He ends by quoting the former Lancet editor, Sir Theodore Fox, who is notorious for having asked himself if it would make any difference if he switched piles and published the week's rejected manuscripts. The answer is easy. For a journal like the Lancet the difference would have been noticeable but modest. For a second rank journal the difference would have been enormous. The gradient between the best and the worst papers is much steeper in the second rank journals; some of their best papers will be the top journals' rejects; the others will be much worse. The front ranking journals should overcome any queasiness they may have about throwing out a few good articles along with many poor ones.

One weakness in the journal review system is editors' inability to identify authors who have received useful advice along with a rejection but have not revised before submitting to another journal. To these people ".... science is their own special sport to which they look for vivid experience and the satisfaction of ambition...." Science may satisfy ambition, but it is not a game. An electronic register of reviews of recently rejected manuscripts, available only to editors, would save reviewers duplication of effort and improve editorial standards.

No matter how strongly we may affirm editorial peer review we would do well to heed Lock's sense of openness and uncertainty about it. It can be improved in many ways: by giving reviewers guidelines to distract them from their personal expectations and to focus them on the journal's requirements; by scanning - with the help of the computera wider range of critics and sophisticated readers on the fringes of the subject; by cracking open some of the narrow cliques unable or unwilling to criticise each other's work; and by encouraging the growth of a group of methods reviewersclinical and community epidemiologists-to press researchers to plan and perform better.

Scientists explore the unknown. Their reports should be received by their peers with organised scepticism. Yet there is a collective intelligence of science that stimulates and guides the work of each scientist towards reliable knowledge based on relative truth. Fleck explains with a metaphor:

How does it come about that all rivers finally reach the sea, in spite of perhaps flowing initially in a wrong direction, taking roundabout ways, and generally meandering? There is no such thing as the sea. The area where the waters actually collect is merely called the sea. Provided enough water flows in the rivers and a field of gravity exists, all rivers must finally end up at the sea. ${ }^{4}$

Peer review is the channel that directs the water of scientific research towards the sea. But this is a sea of common understanding, not an ocean of absolute truth.

Peter MORgaN

Scientific Editor,

Canadian Medical Association fournal,

Ottawa,

Ontario K1G 0G8

Canada

1 Lock S. A difficult balance: editorial peer review in medicine. London: Nuffield Provincial Hospitals Trust, 1985.

2 Osmond DH. Malice's wonderland: research funding and peer reviews. $\mathcal{F}$ Neurobiol 1983;14: 95-112.

3 Einstein A. Essays in science. New York: Philosophical Library, 1934:1.

4 Fleck L. The genesis and development of a scientific fact. Chicago: University of Chicago Press, 1979. (Transl of Entstehung und Entwicklung einer wissenschaftlichen Taatsache. Basle: Benno Schwabe, 1935.) 